\title{
O impacto emocional causado pela pandemia do novo coronavírus aos profissionais de enfermagem: Uma revisão integrativa
}

\author{
The emotional impact of the new coronavirus pandemic on nursing professionals: An integrative \\ review
}
El impacto emocional causado por la nueva pandemia del coronavirus en los profesionales de enfermería: Una revisión integrativa

Recebido: 08/06/2021 | Revisado: 13/06/2021 | Aceito: 14/06/2021 | Publicado: 27/06/2021

\author{
Fernando da Silva Brito \\ ORCID: https://orcid.org/0000-0002-9832-1405 \\ Faculdade Independente do Nordeste, Brasil \\ E-mail: Fernando_brito_10@hotmail.com \\ Anderson Pereira Souza \\ ORCID: https://orcid.org/0000-0001-5819-4088 \\ Faculdade Independente do Nordeste, Brasil \\ Universidade Estadual do Sudoeste da Bahia, Brasil \\ E-mail: andersonpereira@fainor.com.br \\ E-mail: andersonpereira@uesb.edu.br
}

\begin{abstract}
Resumo
No ano de 2019 surgiu uma patologia chamada de COVID-19, causada pelo SARS-COV 2 (novo coronavírus) que tem origem viral com alto poder de transmissibilidade e contágio. Os principais meios de contaminação são através da tosse, espirro, contato físico e secreções liberadas. Os principais meios de redução da disseminação é através do uso de máscara, isolamento social, distanciamento social e higienização das mãos com água e sabão ou álcool 70\%. Com isso, vale ressaltar a importância de analisar os principais impactos emocionais que essa enfermidade causou aos profissionais de enfermagem. Objetivo: analisar, à luz da literatura, os principais impactos emocionais provocados pela pandemia do novo coronavírus aos profissionais de enfermagem. Metodologia: Trata-se de uma pesquisa de revisão de literatura, com caráter descritivo e abordagem quantitativa. Resultados: Foram escolhidos 15 artigos sobre o tema proposto, no qual foi observado a importância de um cuidado especial aos profissionais da saúde que sofrem com impactos psicológicos para que eles contribuam com o cuidado a população de uma forma geral. Considerações finais: O COVID-19 é uma patologia que traz grandes impactos a saúde mental dos profissionais de saúde, devido ao maior risco de contaminação e transmissibilidade.
\end{abstract}

Palavras-chave: Pandemia COVID-19; Equipe de Enfermagem; Emocionais; Pandemia.

\begin{abstract}
In 2019, a pathology called COVID-19 appeared, caused by SARS-COV 2 (new coronavirus) that has a viral origin with high transmission and contagion power. The main means of contamination are through coughing, sneezing, physical contact and released secretions. The main means of reducing dissemination is through the use of masks, social isolation, social distance and hand hygiene with soap and water or $70 \%$ alcohol. Thus, it is worth emphasizing the importance of analyzing the main emotional impacts that this disease caused to nursing professionals. Objective: to analyze, in the light of the literature, the main emotional impacts caused by the new coronavirus pandemic on nursing professionals. Methodology: This is a literature review research, with a descriptive character and a quantitative approach. Results: 15 articles were chosen on the proposed topic, in which the importance of special care for health professionals who suffer from psychological impacts was observed, so that they contribute to the care of the population in general. Final considerations: COVID-19 is a pathology that has great impacts on the mental health of health professionals, due to the greater risk of contamination and transmissibility.
\end{abstract}

Keywords: COVID-19 pandemic; Nursing team; Emotional; Pandemic.

\section{Resumen}

En 2019 apareció una patología denominada COVID-19, provocada por el SARS-COV 2 (nuevo coronavirus) que tiene un origen viral con alto poder de transmisión y contagio. Los principales medios de contaminación son la tos, los estornudos, el contacto físico y las secreciones liberadas. La principal vía para reducir la diseminación es mediante el uso de máscaras, el aislamiento social, la distancia social y la higiene de manos con agua y jabón o alcohol al $70 \%$. Por ello, cabe destacar la importancia de analizar los principales impactos emocionales que esta enfermedad provocó 
en los profesionales de enfermería. Objetivo: analizar, a la luz de la literatura, los principales impactos emocionales provocados por la nueva pandemia de coronavirus en los profesionales de enfermería. Metodología: Se trata de una investigación de revisión de la literatura, con carácter descriptivo y enfoque cuantitativo. Resultados: Se eligieron 15 artículos sobre el tema propuesto, en los que se observó la importancia de la atención especial a los profesionales de la salud que sufren impactos psicológicos, para que contribuyan al cuidado de la población en general. Consideraciones finales: COVID-19 es una patología que tiene grandes impactos en la salud mental de los profesionales de la salud, debido al mayor riesgo de contaminación y transmisibilidad.

Palabras clave: Pandemia de COVID-19; Equipo de enfermería; Emocional; Pandemia.

\section{Introdução}

Sabe-se que a COVID-19, doença provocada pelo vírus SARS-COV 2, se espalhou rapidamente devido o poder de transmissão e contágio entre as pessoas através do contato físico, espirros, tosse e secreções liberadas, agravados pela inexistência da vacina e de medicamentos cientificamente comprovados para o tratamento eficaz contra essa enfermidade. A prevenção momentânea é a melhor forma de combater a pandemia, que exige o isolamento social, uso de máscara, higienização das mãos com água e sabão ou com uso do álcool gel 70\%, além de equipamentos de proteção individual (EPIS) (Brasil, 2020).

No mês de março de 2020 a pandemia se instalou com grande aumento no número de casos no Brasil, além de outros países, o que levou os hospitais públicos e privados a realizar uma busca de profissionais da saúde, inclusive enfermeiros, com o intuito de contratá-los para atuar na linha de frente no combate a pandemia da COVID-19. As pessoas contaminadas, em sua maioria foram inicialmente pessoas assintomáticas e com boa recuperação, entretanto, muitos indivíduos infectados apresentaram uma evolução sintomática, precisando de oxigênio ou ventilação, pois a enfermidade pode provocar a falência de diversos órgãos, induzindo principalmente uma insuficiência respiratória, conduzindo muitos pacientes ao óbito. Assim, os profissionais de saúde, por estar diretamente inserido no campo de trabalho e em contato com a população, estão sendo expostos à contaminação, com riscos de apresentar sintomas mais severos como o desenvolvimento de síndrome respiratória aguda (Verbeek et al., 2020).

A pandemia do COVID-19 exigiu recursos governamentais para o combate mais intenso da doença e medidas mais drásticas para a prevenção da mesma. A ausência de equipamentos e recursos adequados para realização de um trabalho de qualidade levantou na sociedade diversas críticas em função de não existir uma política pública de saúde para o melhor enfrentamento e combate da enfermidade oferecida pelos órgãos públicos federais, estaduais e municipais da saúde (Santana et al., 2020).

Neste contexto, entende-se que o profissional da enfermagem por se encontrar na linha de frente dos atendimentos de combate a pandemia do novo coronavírus, estão sujeitos a ser acometidos por fatores psicoemocionais como o medo, a ansiedade, a depressão e insônia, além, da possibilidade da sensação de esgotamento físico e mental, perda de sentido e distanciamento emocional devido à realização das suas atividades de atendimentos nas unidades de saúde hospitalares ou ambulatoriais com pacientes potencialmente infectados pelo vírus (Bao et al e $\mathrm{Li}$ et al., 2020). Esse quadro tornam-se possíveis consequências relevantes na vida do mesmo, pela sobrecarga e pressão enfrentadas.

Ademais, cabe salientar que a possibilidade de desenvolvimento de transtornos psicológicos pelo profissional de saúde em determinado momento deve ser visualizado pelos administradores, governantes e/ou responsáveis. Dessa forma, requer a necessidade de atenção, a fim de minimizar ao máximo a exposição dos mesmos a fatores de riscos que possam prejudicar o desenvolvimento de suas atividades cotidianas, como quando procuram auxiliar o indivíduo doente. Além disso, esses profissionais precisam lidar com novas medidas de segurança, em muitos casos o isolamento dos familiares e amigos. Portanto, diversas situações que podem condicionar o trabalhador ao estresse constante e dificultar a compreensão de que precisa reservar um tempo para descanso e contatos com pessoas próximas, mesmo que através das redes sociais, melhoria na 
alimentação, evitar uso de álcool, determinadas drogas e até mesmo seguir um acompanhamento psicológico (Brasil, 2020).

A discussão do assunto até aqui apresentado demonstra a necessidade de maiores informações sobre a repercussão da pandemia no desenvolvimento das atividades cotidianas e os impactos psicofísicos gerados na vida do profissional da enfermagem. Neste contexto, este estudo apresenta como objetivo geral analisar, à luz da literatura, os principais impactos emocionais provocados pela pandemia do novo coronavírus aos profissionais de enfermagem.

\section{Metodologia}

Trata-se de uma pesquisa de revisão de literatura, com caráter descritivo e abordagem quantitativa. A amostra do presente estudo, foi levantada a partir de busca nas bases de dados Google Acadêmico, ScieLo, Ministério da Saúde, Organização Mundial da Saúde (OMS), Organização Pan-Americana (OPAS), LILACS, com os seguintes descritores: COVID-19, Pandemia, Saúde Mental, Profissionais da Saúde (Pereira A. S. et al., 2018)

Em relação ao cruzamento de descritores Biblioteca Virtual em Saúde (BVS), Pandemia e COVID-19, foi encontrado 60.191 resultados, Pandemia e Profissionais da Saúde 2.891, Pandemia e Saúde Mental 3.817, COVID-19 e Profissionais da Saúde 2.939, COVID-19 e Saúde mental 4.017, Profissionais da Saúde e Saúde Mental 33.239.

Os critérios de exclusão utilizados foram os artigos com mais de 5 anos de publicação e que não contribuem com os objetivos trabalhados. Já os critérios de inclusão foram os artigos com até 5 anos de publicação e que correspondiam com os objetivos desejados.

Após a aplicação dos critérios de inclusão e exclusão foram selecionados para este estudo 15 artigos, em idioma inglês e português, foi realizado pesquisa de artigos no período entre Agosto de 2020 e Maio de 2021, ressalto que o período de publicação dos artigos foi entre os anos de 2017 e 2020.

A análise dos dados foi realizada através de um quadro construído pelo autor do presente trabalho no programa Word 2010, com os tópicos: Ano de Publicação dos Artigos, Autor, Título, Desenho do Estudo, Objetivos e Resultados, com o intuito de analisar o quantitativo dos profissionais com os impactos da pandemia do COVID-19. Para realização da pesquisa foi respeitado todos os preceitos legais relacionados à atenção da citação dos autores para elaboração do artigo.

\section{Resultados e Discussão}

Foram encontrados centenas de artigos pertencentes ao tema na busca nas bases de dados PubMed, LILACS, Scielo. Pertinentes aos critérios de inclusão e exclusão foram selecionados 15 artigos, sites e resoluções confiáveis, tendo um total de 23 literaturas utilizadas para a construção do artigo. No Quadro 1 foram listados os artigos que fazem parte da amostra.

Quadro 1- Distribuição dos dados de acordo com as bases de dados.

\begin{tabular}{|c|c|c|c|c|}
\hline ANO & AUTOR & TÍTULO & OBJETIVO & RESULTADO \\
\hline 2020 & Barbosa DJ, et al. & $\begin{array}{l}\text { Fatores de estresse } \\
\text { nos profissionais de } \\
\text { enfermagem no no } \\
\text { combate à pandemia } \\
\text { da COVID-19: síntese } \\
\text { de evidências }\end{array}$ & $\begin{array}{l}\text { Identificar os principais } \\
\text { efeitos psicológicos da } \\
\text { pandemia da COVID } 19 \text { nos } \\
\text { profissionais } \\
\text { enfermagem }\end{array}$ & $\begin{array}{l}\text { Foi observado sobre carga de trabalho } \\
\text { pelos profissionais, medo incessante } \\
\text { de contaminar si próprio e seus } \\
\text { familiares, desatenção dos órgãos } \\
\text { governamentais são fatores } \\
\text { primordiais que geram estresse aos } \\
\text { profissionais de enfermagem. }\end{array}$ \\
\hline 2020 & Bao, Y. et al. & $\begin{array}{l}\text { 2019-nCoV } \\
\text { epidemic:address } \\
\text { mental health care to } \\
\text { empower society }\end{array}$ & $\begin{array}{l}\text { Verificar os principais } \\
\text { cuidados na saúde mental } \\
\text { dos profissionais de } \\
\text { enfermagem }\end{array}$ & $\begin{array}{l}\text { Foi abordados cuidados que devem } \\
\text { ser empregado na sociedade diante da } \\
\text { pandemia do covid } 19 \text {. }\end{array}$ \\
\hline
\end{tabular}




\begin{tabular}{|c|c|c|c|c|}
\hline 2020 & $\begin{array}{l}\text { Ho CS, Chee CY \& } \\
\text { Ho RC. }\end{array}$ & $\begin{array}{l}\text { Mental Health } \\
\text { Strategies to Combat } \\
\text { the Psychological } \\
\text { Impact of COVID-19 } \\
\text { BeyondParanoia and } \\
\text { Panic }\end{array}$ & $\begin{array}{l}\text { Analisar os medos e anseios } \\
\text { diante do COVID- } 19 .\end{array}$ & $\begin{array}{l}\text { O principais fatores relatado no artigo } \\
\text { foi o medo e a disseminação da } \\
\text { patologia, além da falta de } \\
\text { informação perante os governantes, } \\
\text { fakes News trazendo um maior } \\
\text { impacto as pessoas, falta de apoio e } \\
\text { maior exposição ao vírus pelos } \\
\text { profissionais de saúde. }\end{array}$ \\
\hline 2020 & $\begin{array}{l}\text { Kang L, Ma S, Chen } \\
\text { M, Yang J, Wang Y } \\
\text { \& Li R. }\end{array}$ & $\begin{array}{l}\text { Impact on mental } \\
\text { health and perceptions } \\
\text { of psychological care } \\
\text { among medical and } \\
\text { nursing staff in } \\
\text { Wuhan during the } \\
2019 \text { novel } \\
\text { coronavirus disease } \\
\text { outbreak: A cross- } \\
\text { sectional study. }\end{array}$ & $\begin{array}{l}\text { Identificar o estado de } \\
\text { saúde mental da equipe } \\
\text { médica e de enfermagem } \\
\text { em Wuahan; }\end{array}$ & $\begin{array}{l}\text { O estudo recaiu sobre as mulheres } \\
\text { jovens }(85 \%) \text {, no qual } 36,4 \% \text { do total } \\
\text { de pessoas entrevistadas apresentaram } \\
\text { distúrbios mentais leve, } 22,4 \% \\
\text { distúrbio moderado, } 6,2 \% \text { distúrbio } \\
\text { grave, na sequencia imediata da } \\
\text { epidemia viral. }\end{array}$ \\
\hline 2020 & Lima, C.K.T. et al. & $\begin{array}{lr}\text { The } & \text { emotional } \\
\text { impacto } & \text { of } \\
\text { coronavirus } & 2019- \\
\text { nCoV } & \text { new } \\
\text { Coronavírus disease). }\end{array}$ & $\begin{array}{l}\text { Como lidar melhor com os } \\
\text { problemas psicológicos } \\
\text { urgentes das pessoas } \\
\text { envolvidas na epidemia de } \\
\text { COVID-19, um novo } \\
\text { modelo de intervenção em } \\
\text { crises psicológicas foi } \\
\text { desenvolvido através do uso } \\
\text { da tecnologia da internet. }\end{array}$ & $\begin{array}{l}\text { As populações de pacientes que } \\
\text { podem requerer intervenções } \\
\text { personalizadas são adultos mais } \\
\text { velhos e trabalhadores migrantes } \\
\text { internacionais. Os adultos mais } \\
\text { velhos com condições psiquiátricas } \\
\text { podem estar passando por mais } \\
\text { sofrimento. A epidemia de COVID- } \\
19 \text { ressaltou lacunas potenciais nos } \\
\text { serviços de saúde mental durante as } \\
\text { emergências. }\end{array}$ \\
\hline 2017 & Leonelli, L.B. et al. & $\begin{array}{l}\text { Estresse percebido em } \\
\text { profissionais da } \\
\text { estratégia da saúde da } \\
\text { família }\end{array}$ & $\begin{array}{l}\text { Avaliar o estresse percebido } \\
\text { de profissionais da ESF e } \\
\text { associação com } \\
\text { caracteristicas das equipes. }\end{array}$ & $\begin{array}{l}\text { Menor estresse percebido foi em } \\
\text { viuvos, observar que com niveis mais } \\
\text { elevados de estresse tem mais } \\
\text { probabiidade de obter problemas } \\
\text { crônico de saúde. }\end{array}$ \\
\hline 2020 & Li, Z. et al. & $\begin{array}{l}\text { Vicarious } \\
\text { traumatization in the } \\
\text { general public, } \\
\text { members, and non- } \\
\text { members of medical } \\
\text { teams aiding in } \\
\text { COVID-19 control. } \\
\text { Brain, Behavior, and } \\
\text { Immunity. }\end{array}$ & $\begin{array}{l}\text { Identificar o estado de } \\
\text { saúde mental da equipe } \\
\text { médica e de enfermagem de } \\
\text { wuahan, a eficácia do } \\
\text { psicológico, atendimento } \\
\text { acessado er suas } \\
\text { necessidades } \\
\text { atendimento psicológico. de }\end{array}$ & $\begin{array}{l}\text { Mostraram uma diferença estatística } \\
\text { na classificação hospitalar, } \\
\text { departamentos e títulos profissionais } \\
\text { entre enfermeiros da linha de frente e } \\
\text { não-linha de frente. }\end{array}$ \\
\hline 2020 & Qian, M. et al. & $\begin{array}{l}\text { Psychological } \\
\text { responses, behavioral } \\
\text { changes and public } \\
\text { perceptions during the } \\
\text { early phase of the } \\
\text { COVID-19 outbreak } \\
\text { in China: a population } \\
\text { based cross-sectional } \\
\text { survey }\end{array}$ & $\begin{array}{l}\text { Para investigar as respostas } \\
\text { psicológicas } \\
\text { comportamentais à ameaça } \\
\text { de infecções por SARS- } \\
\text { CoV-2 e suas associações } \\
\text { com as percepções públicas } \\
\text { na China }\end{array}$ & $\begin{array}{l}\text { As taxas de prevalência de ansiedade } \\
\text { moderada ou grave foram } 32,7 \% \text {, } \\
\text { entre os participantes de Wuhan } \\
20,4 \% \text {, entre os participantes de } \\
\text { Xangai } 78,6 \% \text {. Para ambas as } \\
\text { medidas, os participantes de Wuhan } \\
\text { foram mais responsivos ao surto. }\end{array}$ \\
\hline 2020 & $\begin{array}{l}\text { Ribeiro, Adalgisa. et } \\
\text { al. }\end{array}$ & $\begin{array}{l}\text { Saúde e segurança de } \\
\text { profissionais de saúde } \\
\text { no atendimento a } \\
\text { pacientes no contexto } \\
\text { da pandemia de } \\
\text { Covid-19: revisão de } \\
\text { literatura. }\end{array}$ & $\begin{array}{l}\text { Analisar a produção } \\
\text { científica sobre a saúde que } \\
\text { atendem pacientes no } \\
\text { contexto da Pandemia do } \\
\text { Covid-19. }\end{array}$ & $\begin{array}{l}\text { O acervo analisou profissionais } \\
\text { médicos e enfermeiros que trabalham } \\
\mathrm{e} \text { atuam em hospitais, abordando } \\
\text { conhecimentos sobre a Covid e } \\
\text { atitudes dos profissionais, caso de } \\
\text { Covid na equipe de trabalhadores da } \\
\text { saúde ocupacional. }\end{array}$ \\
\hline
\end{tabular}




\begin{tabular}{|c|c|c|c|c|}
\hline 2018 & Ruback, S.P. et al. & $\begin{array}{l}\text { Estresse e síndrome } \\
\text { de burnout em } \\
\text { profissionais de } \\
\text { enfermagem que atua } \\
\text { na nefrologia: uma } \\
\text { revisão integrativa. }\end{array}$ & $\begin{array}{l}\text { Identificar a produção } \\
\text { científica relacionada à } \\
\text { Burnout e estresse em } \\
\text { trabalhadores } \quad \text { de } \\
\text { enfermagem da nefrologia; }\end{array}$ & $\begin{array}{l}\text { Pacientes apesentaram altos níveis de } \\
\text { estresse e/ou burnout entre } \\
\text { enfermeiros da hemodiálise e cinco } \\
\text { apontaram o burnout abaixo da média } \\
\text { dos países de origem ou comparados } \\
\text { a outros setores de cuidado em saúde }\end{array}$ \\
\hline 2020 & Schmidt, Beatriz et al. & $\begin{array}{l}\text { Saúde Mental e } \\
\text { Intervenções } \\
\text { Psicológicas Diante } \\
\text { da Pandemia do Novo } \\
\text { Coronavírus (COVID- } \\
\text { 19). }\end{array}$ & $\begin{array}{l}\text { Sistematizar conhecimentos } \\
\text { sobre implicações na saúde } \\
\text { mental e intervenções } \\
\text { psicológicas diante da } \\
\text { pandemia do novo } \\
\text { coronavírus. }\end{array}$ & $\begin{array}{l}\text { Foi discutido pelos presentes autores } \\
\text { as implicações da pandemia na saúde } \\
\text { mental, identificação de grupos } \\
\text { prioritários e orientações sobre } \\
\text { intervenções psicológicas, } \\
\text { considerando particularidades da } \\
\text { população geral e dos profissionais da } \\
\text { saúde. }\end{array}$ \\
\hline 2017 & $\begin{array}{l}\text { VIEIRA NF, } \\
\text { Nogueira-da-Terra } \\
\text { FS. }\end{array}$ & $\begin{array}{l}\text { Avaliação do estresse } \\
\text { entre os enfermeiros } \\
\text { hospitalares }\end{array}$ & $\begin{array}{l}\text { Avaliar o estresse entre os } \\
\text { enfermeiros de instituições } \\
\text { hospitalares públicas e } \\
\text { privadas. }\end{array}$ & $\begin{array}{l}\text { Encontrou-se um nível de estresse } \\
\text { médio entre os enfermeiros, } \\
\text { destacando nível alto em três } \\
\text { domínios da escala: as atividades } \\
\text { relacionadas ao funcionamento da } \\
\text { unidade, administração de pessoal e } \\
\text { coordenação das atividades da } \\
\text { unidade. }\end{array}$ \\
\hline 2020 & $\begin{array}{l}\text { Wang, C., Pan, R., } \\
\text { Wan, X., Tan, Y., Xu, } \\
\text { L., Ho, C. S., \& Ho, } \\
\text { R. C. }\end{array}$ & $\begin{array}{l}\text { Imediate } \\
\text { psychological } \\
\text { responses and } \\
\text { associated factors } \\
\text { during the initial stage } \\
\text { of the } 2019 \\
\text { coronavirus disease } \\
\text { (COVID-19) } \\
\text { epidemic among the } \\
\text { general population in } \\
\text { china. }\end{array}$ & $\begin{array}{l}\text { Pesquisar o público em } \\
\text { geral em Chinato e } \\
\text { compreender melhor seus } \\
\text { níveis de impacto } \\
\text { psicológico, ansiedade, } \\
\text { depressão e estresse durante } \\
\text { o estágio inicial do surto de } \\
\text { COVID-19. }\end{array}$ & $\begin{array}{l}\text { No total, } 53,8 \% \text { dos entrevistados } \\
\text { classificaram o impacto psicológico } \\
\text { do surto como moderado ou grave; } \\
16,5 \% \text { relataram sintomas depressivos } \\
\text { moderados a graves; } 28,8 \% \text { relataram } \\
\text { sintomas de ansiedade moderados a } \\
\text { graves; e } 8,1 \% \text { relataram níveis de } \\
\text { estresse moderado a grave }\end{array}$ \\
\hline 2020 & Zhao, Lu R, X \& Li J. & $\begin{array}{l}\text { Caracterização } \\
\text { genômica } \\
\text { epidemiologia do } \\
\text { novo coronavírus de } \\
\text { 2019: implicações } \\
\text { para as origens do } \\
\text { vírus e ligação ao } \\
\text { recptor. }\end{array}$ & $\begin{array}{l}\text { Analisar os aspectos } \\
\text { filogeneticos desses } \\
\text { genomas de covid-19 e de } \\
\text { outros coronavirus para } \\
\text { determinar a história } \\
\text { evolutiva e tentar barra-lo. }\end{array}$ & $\begin{array}{l}\text { O sequenciamento obtido foram } \\
\text { extremamente semelhante com dois } \\
\text { coronavirus derivados de morcegos } \\
\text { em uma amostra coleta em } 2018 \text { no } \\
\text { leste da China. Mesmo assim, } \\
\text { estavam distantes no sequenciamento } \\
\text { genético com os vírus SARS-COV E } \\
\text { MERS-COV. A analise revelou que o } \\
\text { Sars-cov2 caiu dentro do subgênero } \\
\text { sarbecovir do gênero } \\
\text { Betacoronavirus. }\end{array}$ \\
\hline
\end{tabular}

Fonte: $\mathrm{O}$ autor.

A patologia surgiu pela primeira vez na província de Wuhan na China no Ano de 2019, sendo configurada como uma doença nova, diferenciada daquelas provocadas em consequência dos outros tipos de coronavirus. Atualmente o homem vivencia um momento de grandes desafios em decorrência da pandemia do COVID-19, provocado pelo Severe Acute Resperatory Syndrome Coronavírus 2 (SARS-COV 2). A doença trata de um vírus contagioso e de rápida disseminação entre uma pessoa e outra através do contato físico, podendo o paciente contaminado ser assintomático ou não, exigindo medidas de prevenções como a higienização das mãos, isolamento social e evitar aglomeração (Lu, Zhao, Li et al., 2020).

Dessa forma, o cotidiano da população mudou nos últimos meses, causando pânico por não existir um estudo cientifico que pode comprovar a eficácia da vacina, pois pesquisas se encontram em andamento e buscam uma solução para minimizar a contaminação pelo vírus. Deve salientar que enquanto não concluir os estudos, os órgãos governamentais 
precisam manter o cidadão informado e orientado sobre as medidas de prevenções, assim como, ter o esclarecimento de que o isolamento intensifica os sentimentos de medo, tristeza, ansiedade, solidão, depressão e insônia, impactando seu bem estar (OPAS, Wang D, Hu C et al., 2020).

A rápida disseminação da patologia e o aumento no número de casos, na maioria das vezes equivocada, é um grande influenciador para mudanças comportamentais e causador de impactos psicológicos. A taxa de prevalência de ansiedade moderada e grave foi em torno de $33 \%$ dos participantes, percebe-se uma elevada taxa em relação a comprometimento psicológico. (Qian et al.,2020; Lima et al., 2020).

Estudos realizados na Europa, afirmam que após o surto de SARS-COV 2, foi identificado que o nível de estresse diário pode ser um grande fator de depressão na população que esteja em quarentena ou isolamento social. Além disso, foi descoberto fatores psicológicos como medo, tensão, raiva e desconfiança durante o isolamento (Kim et al., 2018).

Alguns aspectos foram relatados para um melhor enfrentamento ao COVID-19, como treinamento adequado dos profissionais, encorajamento para a busca de ajuda psicológica diante da dificuldade de lidar com as emoções e adversidades, fornecimento de livros sobre saúde mental (com intervenções), mensagem de ajuda terapêutica e aconselhamento. Um dos estudos após realizar essas intervenções terapêuticas afirma que esses recursos são importantes para aliviar a psicopatologia, melhorar a saúde psicossocial, físico e mental. (Kang et al.,2020)

Smith e Freedman (2020) relata que as mídias sociais oficiais ao passar informações corretas sobre o motivo do isolamento evitam falsos rumores na sociedade, diminuindo os riscos de maiores impactos psicológicos, redução do medo, controlando a ansiedade, raiva e estresse. $\mathrm{O}$ apoio de vídeos informativos sobre o manejo ao estresse e ansiedade até o apoio social é primordial para o combate dessa patologia.

The Lancet (2020) afirma que fatores como alta possibilidade de infectar, risco de infecção ao outro, dificuldade com o número de óbitos, sentimento de impotência, dentre outros, são as principais fatores ocasionais de adoecimento do profissional de linha de frente ao combate do COVID-19, em especial profissional da enfermagem.

Cerca de aproximadamente 3,5 milhões de profissionais da saúde, incluindo o enfermeiro, vem deparando com preocupações, anseios e incertezas, afetando a sua saúde psicossocial e emocional nesse momento de pandemia, pois a ausência dos equipamentos de proteção nos atendimentos nas unidades de terapia intensiva, urgência e emergência, resgate, atenção primária e unidade de pronto atendimento, leva a Organização Mundial de Saúde notificar que o profissional de enfermagem estar sendo pressionado com determinadas situações impactantes no seu cotidiano, causando graves problemas psicológicos e ampliando os casos de Síndrome de Burnout, gerando estresse e depressão associados (Ruback et al, 2018).

O COFEN (Conselho Federal de Enfermagem) procurou determinar que a Comissão Nacional de Enfermagem e Saúde Mental oferecesse um atendimento especial aos profissionais de enfermagem que se encontra inseridos na linha de frente no combate ao COVID-19, com base na Lei no 7498/86, a resolução do COFEN no 599/2018 e a resolução COFEN nº 564/2017, onde a lei nº7498/86 dispõe sobre o regulamento da atividade da enfermagem. A resolução COFEN nº 599/2018 que procura estabelecer os preceitos mínimos para uma atenção humanizada e relacionada à saúde psicológica do mesmo, tornando uma base legalizada nos atendimentos, e onde a resolução COFEN nº 564/2017 aprova o código de ética e explicita a base dos acolhimentos (Cofen, 2020).

Após verificações de estratégias para o enfrentamento da pandemia, o atendimento psicológico online é primordial, isso devido a impossibilidade do contato presencial durante o período de quarentena. Autores citam algumas terapias que pode ajudar na melhoria da saúde mental, como a Terapia cognitiva comportamental (colabora mentalmente e fisicamente), pratica de atividade física, yoga, reiki, acupuntura, meditação, dentre outros. As principais questões abordadas no artigo foram o medo e a disseminação de enfermidades, além da falta de informação perante aos governantes, fake News, trazendo grandes impactos psicológicos (HO et al., 2020). 
A pandemia do COVID-19 requer um cuidar especial de atenção ao enfermeiro, referindo no seu aspecto emocional e mental, pois diante do surto epidemiológico ampliou os sintomas de ansiedade, medo, tristeza e depressão, provocados pela perda da qualidade de sono, excesso de trabalho, preocupação, frustação pela ausência da família, riscos de contaminação e proteção inadequada, sofrimento, morte dos pacientes, angústias por não possuir recursos necessários que possam atender aos anseios do profissional e paciente. Diante de determinados impactos enfrentados, deve salientar que grande quantidade de profissionais ficou com traumas psicológicos severos, levando ao consumo exagerado de drogas que pode induzir ao mesmo a ter um efeito de longo prazo (Barbosa et al., 2020).

O profissional enfermeiro atua em uma função que requer cuidados na prevenção de doenças e promoção de saúde, colaborando nas demandas encontradas ao combate a pandemia do coronavirus, relacionadas aos conflitos, pressões, sobrecarga e a responsabilidade exigida pela atividade, buscando de forma incansável a qualidade de um trabalho, que possa atender as necessidades da população. Dessa forma, os governantes e gestores da saúde precisam auxiliar o trabalhador que se encontra na linha de frente no combate ao vírus, pois, a doença em circulação causa grande impacto na vida do profissional, por ter que enfrentar algo desconhecido. Esse processo pode desencadear o desenvolvimento de distúrbios psicológicos severos, sendo viável que o profissional seja preparado e acompanhado com informações, atendimentos psicológicos e ações integrativas com o intuito de manter uma saúde equilibrada, tanto física quanto mental. O estudo avalia ainda o estresse percebido de profissionais da Estratégia da Saúde da Família (ESF) e atenção com as características da equipe, no qual foi observado que o índice de viúvos com nível elevado de estresse é menor em comparação com problemas crônico de saúde. (Leonelli et al., 2017).

O estudo de Ribeiro et al (2020), destaca que o conhecimento alcançado de determinados profissionais como os médicos, enfermeiros entre outros que atuam nas unidades de saúde, deve ser considerado de extrema relevância perante as questões de transmissibilidade, diagnóstico e tratamento ao indivíduo, pois, esses profissionais são desafiados a buscar orientações seguras com o intuito de atender a pessoa que se encontra infectada com a COVID-19, além, de outras patologias que pode elevar o risco nesse quadro, exigindo cuidados na proteção e exposição em relação aos pacientes com diagnóstico positivo para a doença.

Diante disso, relata-se que a discussão do tema é extremamente importante pelo fato da geração de informações fidedignas sobre os impactos que esses profissionais estão sofrendo, e as principais soluções que deverão ser tomadas para que reduza o número de pessoas que sofrem com problemas psicológicos devido a pandemia do novo coronavírus.

\section{Considerações Finais}

Os resultados desta pesquisa evidenciaram que os chamados "guerreiros da enfermagem" lidam com situações de estresse a todo momento, contudo o atual cenário intensificou ainda mais, levando a sérios danos a saúde psicológica destes. Neste cenário, estudiosos começaram a pesquisar as consequências físicas e psicológicas causadas pela pandemia, com o objetivo de trazer recursos para melhorar a saúde mental daquelas que já estão com ela prejudicada e prevenir aqueles que ainda não estão.

Algumas questões foram mencionadas no corpo do texto, como terapias psicossociais, importantes para melhorar a situação do indivíduo que esteja ou é propício adquirir problemas psicológicos. Não se deve esquecer que a enfermagem é uma profissão de linha de frente, com características primordiais do cuidado humanizado, sabe-se que é a profissão que passa maior parte do tempo à beira do leito, por isso da importância do cuidado a esses profissionais para prestarem uma assistência de qualidade.

Diante do exposto, a importância de abordagem do estudo é devido a enormes fragilidades que os profissionais da saúde vem sofrendo nos últimos meses devido a pandemia do novo coronavirus, com pressões psicológicas que comprometem 
o bem estar entre família, amigos e o próprio trabalho. Com isso, sugiro que novos estudos aprofundem sobre os impactos psicoemocionais entre os profissionais de saúde, em especial os enfermeiros e profissionais médicos que fazem parte da linha de frente, mostrando soluções para reduzir os impactos emocionais sofridos por esses profissionais.

Cabe ressaltar ainda, a relevância em se realizar novos trabalhos com a finalidade de identificar os principais fatores que tornam o ambiente de trabalho um meio que propicia distúrbios psicoemocionais, nos diferentes profissionais de saúde que atuam na linha de frente no combate à pandemia do COVID-19 e outras enfermidades que afligem a população. Ademais, a identificação dos profissionais que venha adquirir os impactos psicológicos é de suma importância, para que outros profissionais sejam eles, psicólogos, psiquiatras, ajam imediatamente e evite que tais alterações evolua para uma enfermidade mais grave e severa.

\section{Agradecimentos}

Agradeço a Deus pela força e coragem para continuar minha caminhada em busca do conhecimento, minha família pelo apoio de sempre, a todos da instituição de ensino Faculdade Independente do Nordeste (FAINOR), pela honestidade e compromisso com os discentes e futuros profissionais. Aos professores pela qualidade, experiência e conhecimento transmitido durante cinco anos, em especial, ao Msc Anderson Pereira Souza, obrigado, por tudo, pelo apoio, compressão e paciência.

\section{Referências}

Bao, Y., Sun, Y., Meng, S., Shi, J. \& Lu, L. (2020). 2019-nCoV epidemic: Address mental health care to empower society. The Lancet, 395(10224), e37-e38. https://doi.org/10.1016/S0140-6736(20)30309-3

Barbosa, D.J. et al. (2020). Fatores de estresse nos profissionais de enfermagem no combate à pandemia da COVID-19: síntese de evidências. Com. Ciências Saúde.31:31-47. https://doi.org/10.51723/ccs.v31iSuppl\%201.651

Brasil. Ministério da Saúde (2020). Coronavírus. Brasília, 2020.

Conselho Federal de Enfermagem (2020). Apoio em saúde mental [cited 23 Apr 2020].

Conselho Federal de Enfermagem (2020). Nota Técnica 01/2020 ctas - orientações sobre o novo Coronavírus (covid-19). Brasília, 2020.

Ho, CS., Chee, CY. \& Ho, RC. (2020) Mental health strategies to combat the psychological impact of COVID-19: Beyond paranoia and panic. Annals, Academy of Medicine, Singapore.49 (3): 155-161. PMID:32200399

Kang, L., Ma, S., Chen, M., Yang, J., Wang, Y. \& Li, R. (2020). Impact on mental health and perceptions of psychological care among medical and nursing staff in Wuhan during the 2019 novel coronavirus disease outbreak: A cross-sectional study. Brain Behav Immun. Available from. https://oi.org/10.1016 / j.bbi.2020.03.028

Lancet. (2020). COVID-19: protecting health-care workers.The Lancet, 395(10228), 922. https://doi.org/10.1183/16000617.0068-2020

Leonelli, L.B. et al (2017). Estresse percebido em profissionais da Estratégia Saúde da Família. Rev. bras.epidemiol. [online].vol.20,n.2,pp.286-298.ISSN 1980-5497. https://doi.org/10.1590/1980-5497201700020009

Li, W., Yang, Y., Liu, Z. H., Zhao, Y. J., Zhang, Q., Zhang, L. \& Xiang, Y. T. (2020). Progression of mental health services during the COVID-19 outbreak in China. International Journal of Biological Sciences, 16(10), 1732-1738. https://doi.org/10.7150/ijbs.45120

Li, Z. et al (2020). Vicarious traumatization in the general public, members, and non-members of medical teams aiding in COVID-19 control. Brain, Behavior, and Immunity. https://doi.org/10.1016/j.bbi.2020.03.007

Lima, C.K.T. et al. (2020). The emotional impacto of coronavirus 2019-nCoV (new Coronavírus disease). Psychiatry Research. V. 287. https://doi.org/ 10.1016/j.psychres.2020.112915

Liu, S., Yang, LL., Zhang, CX., Xiang, YT., Liu, Z. \& Hu, S. (2020). 2019 novel coronavirus: online mental health services. Lancet Psychiatry: In press. https://doi.org/10.1016/S2215-0366(20)30077-8

Minayo, M.C. (2001). Pesquisa Social: teoria, método e criatividade. 18ª edição. Petrópolis: Vozes.

Organização Mundial da Saúde (OMS). Organização Pan- Americana de Saúde (OPAS). Folha Informativa COVID-19.

Pereira A. S. et al. (2018). Metodologia da Pesquisa Científica. $1^{\circ}$ edição. Santa Maria, RS: UFSM, NTE.

Qian, M. et al. (2020). Psychological responses, behavioral changes and public perceptions during the early phase of the C0VID-19 outbreak in China: a population based cross - sectional survey. MedRxiv. https://doi.org/10.1101/2020.02.18.20024448 
Research, Society and Development, v. 10, n. 7, e42210716934, 2021

(CC BY 4.0) | ISSN 2525-3409 | DOI: http://dx.doi.org/10.33448/rsd-v10i7.16934

Ribeiro, A.P. et al. (2020). Saúde e segurança de profissionais de saúde no atendimento a pacientes no contexto da pandemia de Covid-19: revisão de literatura. Rev.bras.saúde ocup. Vol.45.p. 01-12. https://doi.org/10.1590/2317-6369000013920

Ruback, S.P. et al. (2018). Estresse e síndrome de burnout em profissionais de enfermagem que atua na nefrologia: uma revisão integrativa.Rev. pesqui.cuid.fundam.(Online); 10(3): 889-899. https://doi.org/10.9789/2175-5361.2018.v10i3.889-899

Schmidt, Beatriz. et al. (2020) Saúde Mental e Intervenções Psicológicas Diante da Pandemia do Novo Coronavírus (COVID-19). Estud.psicol.(Campinas) vol.37. https://doi.org/10.1590/1982-0275202037e200063

Vieira, N.F., Nogueira, D.A., Terra, F.S. (2017) Avaliação do estresse entre os enfermeiros hospitalares. Rev.enferm (UERJ). http://dx.doi.org/10.12957/reuerj.2017.14053

Wang, C. et al. (2020). Immediate psychological responses and associated factors during the initial stage of the 2019 coronavirus disease (COVID-19) epidemic among the general population in china. International Journal of Environmental Research and Public Health, 17(5), 1729. https://oi.org/ 10.3390/ijerph17051729

Wang, D. et al. (2020) Clinical Characteristics of 138 Hospitalized Patients With 2019 Novel Coronavirus-Infected Pneumonia in Wuhan, China. JAMA. https://doi.org/10.1001/ jama.2020.1585

Wilder-Smith, A. \& Freedman, D. O. (2020). Isolation, quarantine, social distancing and community containment: pivotal role for old-style public health measures in the novel coronavirus (2019-nCoV) outbreak. J. Travel Med, 27(2), 1-4. https://doi.org/ 10.1093/jtm/taaa020

Zhao, X. et al. (2020). Genomic characterisation and epidemiology of 2019 novel coronavirus: implications for virus origins and receptor binding. Lanceta 2020. https://doi.org/10.1016/S0140-6736(20)30251-8 